\title{
Three standard management system application in research management
}

\author{
Chen Xi Ying ${ }^{1}$ \\ ${ }^{1}$ China Electric Power Research Institute \\ ${ }^{1}$ Haidian District, Beijing Qinghe Xiaoying Road on the 15th 100192 \\ 1,2 chenxiying@epri.sgcc.com.cn
}

Keywords: Quality; System; Three standard; Research; Internal audit; External audit; Standard Abstract. Currently, three standard management system has been in research management applications, but most of the units due to market demand and passive "pay attention to" quality management system where there is no initiative to the enterprise standard system and quality management together, do not take the initiative to quality Lane Management System Internal and standardization of good conduct self-examination combined with the results of the final audit found only superficial phenomenon, the problem continues to be in a "state fire", and the corporate rich standard resources are in cabinet in "sleep" . Aiming at these problems, from the EPRI three standard management system design, audit and research unit focusing on the actual quality management, quality, internal and external audit and research unit project quality management status, internal management and scientific research units how to combine the actual quality, the use of effectiveness aspects of the "process approach" to establish quality management system is generally step-depth analysis to identify key problems, give solutions, intended to be the "standard" system combined with the actual work to improve the quality management system operation .

\section{Introduction}

Market environment, the enterprise production and business operation in the process of quality management system certification is the most basic requirements. For the standardization good behavior has not been enough to know, enterprise has not put forward the basic requirements to myself. Because the market demand of enterprise at present and passively "attaches great importance to the" quality management system, but not to pay attention to the quality management system operation process should be followed by the "standard" system, not to "standard" system of combined with work reality, which can lead to enterprise in the second and third party audit or internal audit process, audit on-site audit from file, many "fact-finding" can't provide the basis of a judge. In fact now many companies did not make full use of the resources of the enterprise standard system, the "standard" system of combined with actual work to improve the effectiveness of the quality management system. Not actively combine enterprise standard system and quality management system, not the initiative to the quality management system internal audit and inspection standardization good behavior, finally the results of the internal audit is found on the surface of the phenomenon, make quality and problems in a "fire condition, and the enterprise standard resources is in a document" sleep "in the cupboard.

\section{Electrical science college three standard management system}

China electric institute three standard management system, including the quality management system requirements, GB/T, 28001-2011 the occupational health and safety management system requirements GB/T 24001-2004 environmental management system requirements and operation guide, GB/T 22080-2008" information technology security technology of information security management system requirements ". Another management system program files and integrated management manual. Integrated management manual is to build a "three standard" management system effective operation, legal and programmatic document, is to carry out the quality, occupational health and safety, environmental management, information security management system of basic principles and guidelines, as well as for customers, employees, society, and other related parties. Staff and into the 
system within the area of all personnel in accordance with the requirements of the handbook of management, conscientiously carry out. Management system program file is suitable for the hospital management system about the whole process of control process, way and method.

\section{The emphasis of the internal audit the actual quality management and scientific research units}

Although the quality management system internal audit and the actual quality management research unit is their business organization planning and implementation of autonomous behavior, but in the research units to carry out the quality management system internal audit and there are still differences of the two actual quality management.

System establishment and the basis of a review: quality management system internal audit on the basis of the relevant laws, regulations, system, etc. System is the focus of attention: quality management system internal audit focus is in accordance with the relevant standards, regulations, whether can get quality system certification, customer satisfaction for product/service. Scientific research units of the actual quality management focus on how improve internal product quality, achieve economic, efficient, internal satisfaction of interested parties.

The main purpose of the system implementation: mainly used for the quality system certification, improve customer satisfaction for product/service. Scientific research units and effectiveness of the quality management system to the management of documents conformity, correction and improvement, realize the goal of enterprise quality management.

\section{The quality of internal and external audit and research unit project quality management status}

Scientific research units of ministry of science and technology results-based management, namely, the output and quality of project results. As for science and technology project process monitoring, ministry of science and technology project classification, the expert supervision, since the acceptance before acceptance, final concluding acceptance methods such as control. Ann quality department to take the form of internal and external audit annually review the spot check on science and technology project.

The two departments of science and technology project quality concerns and the way of monitoring has its own advantages, from different angles puts forward opinions and requirements for science and technology projects, but there is obvious disadvantage is that the two departments separate checks, for the same project, puts forward the problem not enough system, part of the problem have crossed, repeated several times. More than a project check also burden to a certain project. For now, because the ministry of science and technology to monitor the frequency is higher, and monitoring and the content of the final project will have a direct relationship, through the acceptance is paid great attention to by the project team, and quality department for monitoring frequency is low, it is more important is quality department to monitor whether most of the content of the project through the acceptance, eventually project achievements appraisal and the application does not have any effect. Example: a project output all of the results did not save the corresponding review report, test records, for the arrangement of the plan is not a formal document, but the results of this work on the project finally win, does not have any effect, so can't get the attention of the project leader.

\section{Internal audit and how to combine the actual quality management in scientific research institution}

Suggest that scientific research units quality management system and the combination of science and technology project management requirements, formulate unified standards and monitoring mode, main can be shown as:

First of all, for all kinds of science and technology project to establish a unified monitoring standards: ministry of science and technology, quality department, lab representative form a task force, to science and technology project from feasibility study to apply for, under the contract concluding, each 
procedure should follow what management process, the process of asking for detail discussion, creating an overall science and technology project management discipline. This discipline content of science and technology, all the requirements for quality, and the department of project management, project teams as long as to perform this process file.

Second, the unity of science and technology project management and standard time: if no quarter, according to various projects to check the system, and to monitor the content of the project can meet all the requirements of science and technology department, quality department, monitoring results for the two department unified analysis and application.

Again, unified examination standard, to science and technology projects, proposes a set of evaluation criteria, and the standard to meet the requirements of the school each functional departments, so that you can avoid the same problem repeat points.

Strengthen the education of the basic unit of science and technology management process: a lot of project director just technical expert, lack of project management knowledge, require little attention especially to the court, suggested that school related functional departments to the training of the relevant knowledge on a regular basis.

Improve the incentives of the project manager: project director partial technical light management of an important factor may be a little impact on individual career management, as long as finish the relevant patent, paper is ok. Project is a special kind of process, it is in a certain time, meet the sum of a series of specific target a number of related work. Project in the process of the operation, has many characteristics, such as the unrepeatable, multi-objective and temporary, therefore, the quality of the project management is more complex. As more enterprise business activities involve organized by project, must be carried out to the enterprise all projects within the scope of effective quality control, and in the quality system coordination of project quality management and operating process.

Project manager to organize the implementation of projects and quality control, is responsible for the quality of all activities of the entire project. Three standard quality review is quality department to review management activities in the process of project implementation. Micro design in the process of project implementation process is controlled by the enterprise quality management system, you need to follow the enterprise standard operation process, belonging to the enterprise quality control. Enterprise quality control include major issues in the project, project important progress of confirmation and approval. At project completion stage, quality department, ministry of science and technology, this article analyzes the quality records during project execution, perfecting the reference project process model, .

\section{"Process approach" is adopted to establish the general steps of quality management system}

\section{Describe the process}

ISO/TS16949:2002 4.16 requirements: "the organization must determine the sequence and interaction of these process". Determine the input and output of the process and to each other in a logical sequence and the interaction relations. Adopt the "process path diagram" to show the link sequence and interaction of the process. Determine the specific implementation of each process step, conditions and methods of measurement and control and documented.

\section{The analysis process (for a particular process)}

What is the name of the process (or support customer orientation process)? Process input: what should the process received (such as raw materials, samples, intermediate product, the product requirements, characteristics, acceptance criteria, deliver information and feedback information, the measurement data)? Should deliver what the output of the process: the process (such as samples, ask the product, the final product, feedback, measurement data). This process should do, how to do (procedures, instructions, methods, etc.)? What key indicators or standards to monitor the process use evaluation (targets, indicators, quantitative method)? 


\section{Determine the process of evaluation index and criterion}

ISO/TS16949:2002 $4.1 \mathrm{c}$ requirements: "the organization must be determined to ensure that these processes can run efficiently and control principles and methods of the fog". Efficacy: implement the plan of activity and reach the level of planning results. Each main process to establish scale enterprises index (should support the organization's goals indicators associated with customers as much as possible). For each process, and clear to define the types of indicators:

Effectiveness indexes, using the index report process activities implementation progress and status.

Efficiency indicators: use the index reporting process activities to achieve the result of the relationship between the use of resources.

The use of these indicators, and compared with the goals of the organization. According to input the output of the review process corrective actions or propulsion system of continuous improvement measures are put forward. Measures should be as quantitative as possible (time, quantity, quality/publication, M, cost, customer satisfaction, efficiency, performance, etc.). Cannot be quantified indexes should be through the review to evaluate the effectiveness of the process.

\section{Summary}

Three standard management system has been applied in the management of scientific research, but most of the unit due to market demand and passively "attaches great importance to the" quality management system, not actively combine enterprise standard system and quality management, not actively good behavior standardization for the quality management system internal audit and inspection, finally the results of the internal audit was found on the surface of the phenomenon, the problem is in a state of "fire", and the enterprise standard resources is in a document "sleep" in the cupboard. The above problems, the author of this paper, from the electrical design institute three standard management system, internal audit and scientific research units of the actual quality management focus, quality current situation of internal and external audit and scientific research units of project quality management, internal audit and research how to combine the actual quality management and quality management system set up by adopting the "process approach", analyzing the general steps of find out the key problems and solutions are given to the "standard" system of combined with practical work to improve the effectiveness of the quality management system.

\section{References}

[1] Liao Yong ping. 1 quality management commonly used statistical techniques and methods. Beijing: China science and technology press, 2012

[2] Quality Management kick-out Guidelines for Sustainable Growth [S] , 2003

[3] Quality management system standard GB/F, 19000-2000 GBT19001-2000. Beijing: China standard press, 2001

[4] European Business Review, 2014, 18 (2):84-96

[5]Economics principle [M], Beijing: mechanical industry publishing house, 2013.

[6] Zhang li. Try to talk about quality cost management ji machinery development, 2015 (2) : 121-122.

[7] Jian hua xiao, Li Ren liang. 2000 national quality management system standards to understand and implement [MI] Beijing: China standard press, 2011.

[8]Marlin kuo ying. Total quality management basic knowledge [M]. Beijing: China economic publishing house. 2013.

[9] Jian tao zhou. Us-Japan enterprise quality management characteristics [J]. China quality and technical supervision, 2004, (10).

[10] Ichiro Masaki. A brief History of ITS [R]. USA: Massachusetts Institute of Technology, 1999 